International Review of Research in Open and Distributed Learning Volume 20, Number 1

February - 2019

\title{
Editorial - Volume 20, Issue 1
}

\section{Rory McGreal}

Co-Editor

Welcome to this first edition of IRRODL for 2019. I would like to wish all of our readers and their families a very happy, thought-filled and prosperous year. This year IRRODL brings significant changes as our coEditor of many years, Dianne Conrad, has resigned. She will be missed. Her efforts have been instrumental in turning IRRODL into a leading journal in the open and distributed learning field. We would like to thank Dianne for her leadership and wish her all the best in her retirement.

In the meantime, we have been fortunate to procure the services of an excellent academic and distance educator Dr. Dietmar Kennepohl as interim Co-Editor. Dr. Kennepohl is a professor of Chemistry and former Associate Vice President Academic at Athabasca University. Nearly all of his teaching experience has been in a distributed and online setting and for this, he holds both university and national distance teaching awards. As a chemistry teacher he has a long history of both developing and delivering lab kits, virtual labs, and in other ways meeting the challenges of science "at a distance." Dr. Kennepohl is also a well-published and sought-after presenter at local, national, and international conferences, on relevant topics including learning design, learning outcomes, assessment, PLAR, transfer credit, distance and online education, and emerging educational technologies. His co-edited open access book, Accessible Elements: Teaching Science Online and at a Distance was winner of the Charles A. Wedemeyer Award. His latest book, Teaching Science Online: Practical Guidance for Effective Instruction and Lab Work (2016) is part of the distance education series edited by Michael G. Moore. I am confident that with his participation and the continuing efforts of our experienced IRRODL Manager, Serena Henderson, that IRRODL will continue to be an effective instrument for publishing open and distributed learning research in the coming year.

I would also like to thank all our Editorial Board members for their continuing support. Unfortunately, we lost a board member and leading figure in open education with the passing away of Professor and former Rector Magnificus of the Open University of the Netherlands, Fred Mulder. His passing represents a major loss to the open education community and to our journal.

I would also like to welcome several new members to the IRRODL advisory board. These include a truly international group: Professor Marti Cleveland-Innis is local from Athabasca University and also a guest professor at the Royal Institute of Technology in Sweden; Dr. Catherine Cronin from the National Forum for the Enhancement of Teaching and Learning in Higher Education is from Ireland; Dr. Laura Czerniewicz is Director of the Centre for Innovation and Learning at the University of Cape Town; Dr. Fengliang Li is at the Institute of Education at Tsinghua University, China;distinguished Professor 
Charlotte "Lani" Gunawardena is a participant in the Organization, Information and Learning Sciences (OILS) program at the University of New Mexico, USA; Professor Sana Harbi is Dean of the Higher Institute of Finance and Taxation at the Université de Sousse in Tunisia; Professor Paul Prinsloo is at the University of South Africa (UNISA); and Professor Katherine Wimpenny is at the Centre for Global Learning, Education and Attainment at Coventry University, UK.

Another "thank you" goes out to all of our +500 reviewers from 2018. Due to their efforts and diligence, we were able to publish 80 articles in 2018. A list of 2018 reviewers is available here.

Starting this year, IRRODL shall no longer be accepting submissions describing teaching interventions or surveys on pedagogical approaches that make no reference to student achievement, performance, or retention. An educator is a person, who helps others to acquire knowledge, competences, outcomes, skills, or values. If there is no evidence that such learning acquisition takes place, there is no proof of the educational value of the intervention. Pedagogical research in education must demonstrate that students actually learn something, or not. Negative results that show that a particular intervention resulted in "no achievement" can also be important. Studies on student engagement, attitudes, and satisfaction are only useful for educators insofar as they promote real learning (or not). This is not to argue that the focus of the research must always be on student outcomes, competences, achievement, etc., but rather to suggest that if an investigation into teaching/learning has another focus, there should also be some reference to whether or not learning took place. If there is evidence of actual learning by students (or student retention for example), then research on affective variables such as student engagement, empathy, attitudes, satisfaction, etc. can shed light on these educational fundamentals. What does it matter if a study examines Moore's "transactional distance" or Garrison's "community of inquiry" or constructivism or connectivism or student attitudes, etc., if the research does not also demonstrate that students actually learned something (or not)? These approaches or methodologies can be shown to be useful for educators insofar as they promote real learning. Without any evidence of learning, however, the research is not relevant to a journal about learning.

A study may show that the students and the teacher were all happy with the experience and the students may believe that they have learned something (Kirkpatricks level 1), but without any mention (in whatever form) of actual achievement, the approach/methodology, or the perception of students/teachers is of little, if any, value. However, when combined with data on student achievement/mastery (or not), this research can become important and worthy of attention.

I am beginning to believe that this surfeit of research that ignores actual learning can be traced to the ubiquitous dissemination of support for "learner-centredness." This view places most, if not all, of the educational emphasis on the learner rather than on a focus on learning. This extreme focus on the "learner" has resulted in many researchers all too often ignoring "learning," to the point where entire research interventions do not even mention it. For example, in the pedagogy associated with student satisfaction or teacher caring -- Is empathy always believing the learner? Isn't knowing when you are being played by the student also empathy? Couldn't student achievement be affected positively or negatively independent of student satisfaction? As another example, learning communities may increase interactivity, but does the interaction have an effect, either positive or negative, on student achievement? If it does have a positive effect, then how can we improve learning through more or better quality 
interactions? If there is no positive effect on achievement, we may ask ourselves, why are we doing this? Are there other factors that do increase learning that should be focused on?

Can we become more "learning-centred" where instructors and researchers take a systemic approach, not ignoring the learner, but also possibly (depending on the research focus) including the teacher, the technology, the administration, the learning environment, and even the society - and most importantly the acquisition of learning? Evidence of learning can take many forms; it need not be confined to objective tests or course grades. Performance and skills assessment can be used. Can the learner perform a specified task or tasks? Are learners confident and skilled enough to develop and test a solution to a real problem? Are there identified quality improvements in the skills? Has the learner adopted scientific attitudes? Given a problem, can the student employ critical thinking skills to achieve a resolution?

To be clear, this insistence on reference to student achievement only refers to articles on student interventions and does not include papers that are based on non-pedagogical issues. Other open and distributed education articles (e.g., OER, administration, leadership, retention, etc.) will continue to be considered for review.

After this rather long preamble, I would like to provide a short introduction to this 2019 first edition, which begins with a research analysis, followed by articles on a DE physics lab and a virtual agent. Midcareer adults and health professionals are the subject of the next two articles, while high school parents' engagement is examined in the next one. Learning achievement and performance is the focus of the following articles. Texts, OER, and MOOCs round out this issue ending with a report on personalisation and learning analytics. Finally, Research Notes complete this issue with reports on OER in the small island state of Tonga and training in Greece.

\section{Athabasca} University

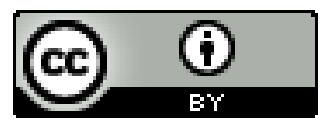

